\title{
Current management of Transient Ischaemic Attacks
}

\author{
Udaya K Ranawaka
}

Department of Medicine, Faculty of Medicine, University of Kelaniya, Sri Lanka.

Correspondence: Prof. Udaya K. Ranawaka

e-mail: udayaran@yahoo.com;udayaran@kln.ac.lk

D https://orcid.org/0000-0002-4050-062X

Submitted on 08.03.2021 and accepted for publication on 20.03.2021

\section{Why talk about TIAs?}

A transient ischaemic attack (TIA) is akin to a smouldering volcano that is waiting to erupt (1), and lead to a devastating stroke that can be fatal in approximately $20 \%$ and disabling in about twothirds (2). About $15-25 \%$ of all ischaemic strokes are preceded by TIAs (3-5). Recent meta-analyses suggest that following a TIA, the risk of ischaemic stroke is $\sim 9 \%$ at 3 months $(6,7)$. Most of this risk is seen in the very early stages after a TIA; $40 \%$ of all strokes during the 30 days after a TIA occur within the first 24 hours (8), and half of all strokes within 3 months after a TIA occur within the first 48 hours (2). Immediate management of TIAs, therefore, would be expected to minimise the risk of stroke. Data from recent studies have confirmed that this indeed is a realistic goal, and have highlighted the importance of emergent evaluation and treatment of TIAs $(9,10)$. This has led to a dramatic change, a virtual paradigm shift, in our approach to the acute management of TIAs, especially over the last two decades $(11,12)$.

\section{Evaluation of TIA - what's new?}

TIA remains a clinical diagnosis, based on the traditional time-based definition of the presence of transient neurological symptoms lasting less than 24 hours. However, in reality, most TIAs resolve within 60 minutes (3). If symptoms last more than 60 minutes, $30-50 \%$ of patients with classically defined TIAs show brain infarction on DW-MRI scanning (13). This has led to a tissue-based definition of TIA being proposed (13), but it is not routinely used in clinical practice due to the need for MRI scanning which has limited availability in many clinical care settings. A TIA is more likely when symptoms clearly indicate a focal origin (hemiparesis, hemisensory symptoms, dysphasia, homonymous hemianopia or monocular visual loss). Non-focal symptoms, such as headache, dizziness, vertigo or confusion make a diagnosis of TIA less likely. It is important to consider and exclude TIA mimics such as hypoglycaemia, migraine aura and seizures $(3,14)$. Neuroimaging, preferably with DW-MRI is recommended. All patients need urgent evaluation for vascular risk factors and the likely underlying aetiology (large artery atherosclerosis, small vessel disease, cardiac source of embolism, or other uncommon causes).

Several risk scoring systems have been used for risk stratification of patients with TIA. The ABCD2 score is the most widely used among these. It stratifies patients into low, moderate or high risk, indicating a 48 -hour stroke risk of $1 \%, 4 \%$ and $8 \%$ respectively (15). The rationale in using scoring systems is to triage patients and identify those requiring immediate evaluation and management. However, recent data suggests that triaging based on scoring systems is not optimal, and over $20 \%$ of recurrent strokes occur in patients classified as 'low risk' $(\mathrm{ABCD} 2$ score $<4)(14,16,17)$. Limiting urgent assessment to TIA patients in moderate or highrisk categories ( $\mathrm{ABCD} 2$ score $\geq 4$ ) would, therefore, miss $20 \%$ of those who would develop early recurrent strokes, and it is now recommended that all TIAs should be considered as 'high risk' deserving urgent attention $(16,18)$.

Modelling analyses had suggested that optimal management could reduce recurrent stroke risk after stroke and TIA by as much as $80-90 \%$ (19). 
Landmark studies such as the EXPRESS study and the SOS-TIA study have demonstrated that such impressive treatment effects are indeed achievable with emergent care of TIAs in specialised TIA clinics $(9,10,20)$. Observational data from longitudinal cohorts such as the TIAregistry.org have confirmed that similar benefits can be attained in real-life clinical care settings $(16,21)$. Current recommendations are that all suspected TIAs should be evaluated within 24 hours by a specialist with experience in stroke care in a dedicated rapidaccess TIA clinic with round-the-clock access or an emergency department $(3,17,18)$.

\section{Management of TIA- what's new?}

Anti-thrombotic treatment (antiplatelet or anticoagulant therapy, depending on aetiology), medical risk factor management and lifestyle modification are the cornerstones of secondary stroke prevention following a TIA.

\section{Anti-thrombotic treatment}

Stroke risk reductions observed in recent times with immediate management of TIAs are largely attributable to the effects of early initiation of antiplatelet treatment of acute non-cardioembolic TIAs (20). The current antiplatelet treatment strategy for TIAs is fashioned on the results of two landmark trials (CHANCE and POINT) (22-24), and pooled analyses of their patient data $(25,26)$. Contemporary recommendations are to initiate acute treatment with dual antiplatelet therapy within 24 hours of symptom onset (with the combination of aspirin 300 $\mathrm{mg}$ stat and $75 \mathrm{mg}$ daily, plus clopidogrel $300 \mathrm{mg}$ stat and $75 \mathrm{mg}$ daily), to be continued for only 3 weeks $(1,3,25,27,28)$. This should be followed by long term antiplatelet treatment. Aspirin is the preferred antiplatelet agent for long term secondary prevention. It is the most effective antiplatelet agent in the acute phase following a TIA where stroke risk reduction is most crucial, and no other single antiplatelet agent performs better than aspirin in the acute phase. $(1,20,25,27)$. Clopidogrel is an effective alternative when aspirin intolerance, allergy or resistance is present. The combination of aspirin and clopidogrel is not recommended for long term secondary prevention, as it is associated with excessive bleeding. $(1,20,25,27)$. Intriguingly, the effect of aspirin is maximal within the first 6 weeks, and appears to wane after about 3 months (20). More interestingly, dipyridamole in combination with aspirin has been shown to be effective in reducing stroke risk after 3 months, especially disabling or fatal ischaemic stroke (20). As such, a combination of aspirin with dipyridamole is likely to be the most effective antiplatelet strategy for long term secondary prevention $(1,20)$. Triple antiplatelet therapy with aspirin, clopidogrel and dipyridamole was studied in the TARDIS trial but was associated with excess bleeding risk (29).

Several newer antiplatelet agents have been studied over the recent years. In the SOCRATES trial, ticagrelor monotherapy failed to show any benefit over aspirin at preventing stroke (30). The THALES trial compared ticagrelor plus aspirin with aspirin alone, and the combination was associated with increased bleeding, especially intracranial bleeding (31). Cilostazol appears to the most promising of the newer antiplatelet agents being studied; a systematic review and meta-analysis has shown it to be more effective than aspirin in reducing the risk of recurrent ischaemic stroke, especially lacunar stroke (32). The data on cilostazol has been mainly from Far Eastern countries where it is widely prescribed, but it is rarely used in other parts of the world.

Anticoagulation is recommended for TIAs of cardioembolic origin, especially non-valvular atrial fibrillation $(3,17)$. Direct oral anticoagulants (DOACs) are preferred over warfarin because of their convenience in use and lower risk of intracerebral haemorrhage.

\section{Riskfactor management}

Appropriate treatment for hypertension and diabetes are of paramount importance. Target blood pressure should be $<140 / 90 \mathrm{mmHg}$, and $<130 / 90 \mathrm{mmHg}$ in the presence of diabetes or small vessel disease $(3,17)$. Intensive lipid-lowering therapy with statins is recommended with a target LDL-cholesterol level of $<70 \mathrm{mg} / \mathrm{dl}$, especially in TIAs due to largeartery atherosclerosis (3). Patients with significant $(>50 \%)$ ipsilateral extracranial carotid artery stenosis should be referred for revascularisation 
(carotid endarterectomy or stenting), which needs to be performed within two weeks of the index TIA $(3,17,18,33)$. Lifestyle changes, such as smoking avoidance or cessation, regular exercise, healthy dietary habits and weight reduction if appropriate, are integral components of secondary prevention.

\section{Can we do better?}

TIAs are mini-strokes, and portend the likelihood of an impending stroke which can be disabling or fatal. Aggressive evaluation and treatment has been shown to be effective in dramatically reducing the risk of stroke following TIA. However, there is clear evidence that much more needs to be done. A systematic review of the time trends in TIA outcomes over the last five decades (1971-2019) has shown that following impressive stroke risk reductions in the early periods, stroke rates have been stagnating over the last decade or so in spite of significant new therapeutic advances (34). Ongoing research will undoubtedly generate new knowledge and new interventions leading to better care, but effective and universal implementation of what we have already learnt over the last two decades would go a long way in preventing smouldering TIAs from erupting as devastating strokes.

\section{References}

1. Hankey GJ. Antithrombotic Therapy for Stroke Prevention. Circulation. 2019; 139(9): 1131-1133. DOI: 10.1161/CIRCULATIONAHA.118.036656.

2. Johnston SC, Gress DR, Browner WS, Sidney S. Shortterm prognosis after emergency department diagnosis of TIA. JAMA. 2000; 284(22): 2901-6.

3. Amarenco P. Transient Ischaemic Attack. New Engl J Med. 2020; 382(20): 1933-1941. DOI: 10.1056/NEJMcp1908837.

4. Rothwell PM, Warlow CP. Timing of TIAs preceding stroke: time window for prevention is very short. Neurology. 2005; 64(5):817-20. DOI: 10.1212/01.WNL.0000152985.32732.EE.

5. Coull AJL, J. K. Rothwell, P. M. Population based study of early risk of stroke after transient ischaemic attack or minor stroke: implications for public education and organisation of services. BMJ. 2004; 328(7435): 326.
6. Hill MD, Yiannakoulias N, Jeerakathil T, et al. The high risk of stroke immediately after transient ischaemic attack: a population-based study. Neurology. 2004; 62(11): 2015 20. DOI: 10.1212/01.wnl.0000129482.70315.2f

7. Giles MF, Rothwell PM. Risk of stroke early after transient ischaemic attack: a systematic review and meta-analysis. Lancet Neurology. 2007; 6(12): 1063-72.

8. Chandratheva A, Mehta Z, Geraghty OC, Marquardt L, Rothwell PM. Population-based study of risk and predictors of stroke in the first few hours after a TIA. Neurology. 2009; 72(22): 1941-7.

9. Rothwell PM, Giles MF, Chandratheva A, et al. Effect of urgent treatment of transient ischaemic attack and minor stroke on early recurrent stroke (EXPRESS study): a prospective population-based sequential comparison. Lancet. 2007;370(9596): 1432-42.

10. Lavallee PC, Meseguer E, Abboud H, et al. A transient ischaemic attack clinic with round-the-clock access (SOSTIA): feasibility and effects. Lancet Neurology. 2007; 6(11): 953-60.

11. Mettananda KCD, Ranawaka UK. The changing face of transient ischaemic attacks. Journal of the Ceylon College of Physicians. 2020; 50(2): 64-68. DOI: $10.4038 /$ jccp.v50i2.7837

12. Mettananda CD, Ranawaka UK. Transient Ischaemic Attacks: It's time for timely action! Ceylon Med J. 2020; 65(1\&2): 5-8. DOI: 10.4038/cmj.v65i1-2.9130.

13. Easton JD, Saver JL, Albers GW, et al. Definition and evaluation of transient ischaemic attack: a scientific statement for healthcare professionals from the American Heart Association/American Stroke Association Stroke Council; Council on Cardiovascular Surgery and Anesthesia; Council on Cardiovascular Radiology and Intervention; Council on Cardiovascular Nursing; and the Interdisciplinary Council on Peripheral Vascular Disease. Stroke. 2009; 40(6): 2276-93.

14. Coutts SB. Diagnosis and Management of Transient Ischaemic Attack. Continuum (Minneap Minn). 2017; 23(1, Cerebrovascular Disease): 82-92. DOI: $10.1212 / \mathrm{CON} .0000000000000424$.

15. Johnston SC, Rothwell PM, Nguyen-Huynh MN, et al. Validation and refinement of scores to predict very early stroke risk after transient ischaemic attack. Lancet, 2007; 369(9558): 283-92. DOI: 10.1016/S01406736(07)60150-0. 
16. Amarenco $\mathrm{P}$, Lavallée $\mathrm{PC}$, Labreuche $\mathrm{J}$, et al. TIAregistry.org Investigators. One-Year Risk of Stroke after Transient Ischaemic Attack or Minor Stroke. $N$ Engl J Med. 2016; 374(16): 1533-42. DOI: 10.1056/NEJMoa1412981.

17. Gomez CR, Schneck MJ, Biller J. Recent advances in the management of transient ischaemic attacks. F1000Res. 2017; 6: 1893. DOI: 10.12688/f1000research.12358.1.

18. National Guideline Centre (UK). Stroke and transient ischaemic attack in over 16s: diagnosis and initial management. London: National Institute for Health and Care Excellence (UK); 2019 May.

19. Hackam DG, Spence JD. Combining multiple approaches for the secondary prevention of vascular events after stroke: a quantitative modeling study. Stroke. 2007; 38(6): 1881-5. DOI: $10.1161 /$ STROKEAHA.106.475525.

20. Rothwell PM, Algra A, Chen Z, Diener HC, Norrving B, Mehta Z. Effects of aspirin on risk and severity of early recurrent stroke after transient ischaemic attack and ischaemic stroke: time-course analysis of randomised trials. Lancet. 2016; 388(10042): 365-375. DOI: 10.1016/S0140-6736(16)30468-8.

21. Amarenco P, Lavallée PC, Monteiro Tavares L, et al. Five-Year Risk of Stroke after TIA or Minor Ischaemic Stroke. New England Journal of Medicine. 2018; 378(23): 2182-90

22. Wang Y, Wang Y, Zhao X, Liu L, Wang D, Wang C, et al. Clopidogrel with Aspirin in Acute Minor Stroke or Transient Ischaemic Attack. New Eng $J$ of Med. 2013; 369(1): 11-9.

23. Johnston SC, Easton JD, Farrant M, et al. Clopidogrel and Aspirin in Acute Ischaemic Stroke and High-Risk TIA. New Eng J of Med. 2018;379(3): 215-25.

24. Johnston SC, Elm JJ, Easton JD, et al; POINT and Neurological Emergencies Treatment Trials Network Investigators. Time Course for Benefit and Risk of Clopidogrel and Aspirin After Acute Transient Ischaemic Attack and Minor Ischaemic Stroke. Circulation. 2019; 140(8): 658-664. DOI: 10.1161/CIRCULATIONAHA 119.040713

25. Pan Y, Elm JJ, Li H, et al. Outcomes Associated With Clopidogrel-Aspirin Use in Minor Stroke or Transient Ischaemic Attack: A Pooled Analysis of Clopidogrel in High-Risk Patients With Acute Non-Disabling Cerebrovascular Events (CHANCE) and Platelet-Oriented
Inhibition in New TIA and Minor Ischaemic Stroke (POINT) Trials. JAMA Neurol. 201; 76(12): 1466-73. DOI: 10.1001/jamaneurol.2019.2531.

26. Hao Q, Tampi M, O'Donnell M, Foroutan F, Siemieniuk RA, Guyatt G. Clopidogrel plus aspirin versus aspirin alone for acute minor ischaemic stroke or high risk transient ischaemic attack: systematic review and meta-analysis. $B M J, 2018 ; 363$ : k5108. DOI: 10.1136/bmj.k5108.

27. Prasad K, Siemieniuk R, Hao Q, et al. Dual antiplatelet therapy with aspirin and clopidogrel for acute high risk transient ischaemic attack and minor ischaemic stroke: a clinical practice guideline. BMJ. 2018; 363: k5130.

28. Xiong Y, Bath PM. Antiplatelet Therapy for Transient Ischaemic Attack and Minor Stroke. Stroke. 2020; 51(11): 3472-3474. DOI: 10.1161/STROKEAHA.120.031763.

29. Bath PM, Woodhouse LJ, Appleton JP, et al. TARDIS Investigators. Antiplatelet therapy with aspirin, clopidogrel, and dipyridamole versus clopidogrel alone or aspirin and dipyridamole in patients with acute cerebral ischaemia (TARDIS): a randomised, open-label, phase 3 superiority trial. Lancet, 2018; 391(10123): 850-859. DOI: 10.1016/S0140-6736(17)32849-0

30. Johnston SC, Amarenco P, Albers GW, et al. SOCRATES Steering Committee and Investigators. Ticagrelor versus Aspirin in Acute Stroke or Transient Ischaemic Attack. New Engl J Med. 2016; 375(1): 35-43. DOI: 10.1056/NEJMoa1603060

31. Johnston SC, Amarenco P, Denison H, et al; THALES Investigators. Ticagrelor and Aspirin or Aspirin Alone in Acute Ischaemic Stroke or TIA. N Engl J Med 2020;383(3):207-217. DOI: 10.1056/NEJMoa1916870.

32. McHutchison C, Blair GW, Appleton JP, et al. Cilostazol for Secondary Prevention of Stroke and Cognitive Decline: Systematic Review and MetaAnalysis. Stroke. 2020; 51(8): 2374-2385. DOI: 10.1161/STROKEAHA.120. 029454.

33. Rerkasem A, Orrapin S, Howard DP, Rerkasem K. Carotid endarterectomy for symptomatic carotid stenosis. Cochrane Database Syst Rev. 2020; 9: CD001081. DOI: 10.1002/14651858.CD001081.pub4.

34. Shahjouei S, Sadighi A, Chaudhary D, et al. A 5-Decade Analysis of Incidence Trends of Ischaemic Stroke After Transient Ischaemic Attack: A Systematic Review and Meta-analysis. JAMA Neurol. 2021; 78(1): 77-87. DOI: 10.1001/jamaneurol.2020.3627. 